\title{
Sturing verhindert leerprocessen
}

Citation for published version (APA):

Horstman, K., Lecluijze, I., Penders, B., \& Feron, F. (2014). Sturing verhindert leerprocessen. Jeugdbeleid, 8(2), 9-16. https://doi.org/10.1007/s12451-014-0015-9

Document status and date:

Published: 01/01/2014

DOI:

10.1007/s12451-014-0015-9

Document Version:

Publisher's PDF, also known as Version of record

Document license:

Taverne

\section{Please check the document version of this publication:}

- A submitted manuscript is the version of the article upon submission and before peer-review. There can be important differences between the submitted version and the official published version of record.

People interested in the research are advised to contact the author for the final version of the publication, or visit the DOI to the publisher's website.

- The final author version and the galley proof are versions of the publication after peer review.

- The final published version features the final layout of the paper including the volume, issue and page numbers.

Link to publication

\footnotetext{
General rights rights.

- You may freely distribute the URL identifying the publication in the public portal. please follow below link for the End User Agreement:

www.umlib.nl/taverne-license

Take down policy

If you believe that this document breaches copyright please contact us at:

repository@maastrichtuniversity.nl

providing details and we will investigate your claim.
}

Copyright and moral rights for the publications made accessible in the public portal are retained by the authors and/or other copyright owners and it is a condition of accessing publications that users recognise and abide by the legal requirements associated with these

- Users may download and print one copy of any publication from the public portal for the purpose of private study or research.

- You may not further distribute the material or use it for any profit-making activity or commercial gain

If the publication is distributed under the terms of Article $25 \mathrm{fa}$ of the Dutch Copyright Act, indicated by the "Taverne" license above, 


\title{
Sturing verhindert leerprocessen
}

\author{
Klasien horstman, Inge lecluijze, Bart Penders, Frans Feron *
}

\begin{abstract}
De wet Verwijsindex Risico jongeren is in 2010 aangenomen. Die wet verplicht gemeenten om afspraken te maken met organisaties die met kinderen werken om zich, meestal via aan lokale index, aan te sluiten op de landelijke Verwijsindex. De index is opgenomen in de nieuwe Jeugdwet. De Verwijsindex wordt gepresenteerd als een 'simpel instrument' dat er voor zal zorgen dat er 'geen kinderen tussen wal en schip vallen'.

Vroegsignalering van risicokinderen in de Verwijsindex komt volgens de auteurs neer op het geven van een ongefundeerd professioneel oordeel, wat leidt tot professionele weerstand. Zij vragen zich af of de index een databank van vermoedens is over mogelijke problemen voor een kind in-de-toekomst of een systeem voor hulpverleners voor coördinatie van concrete zorg in het hier-en-nu. Door de oproep aan professionals om meer te signaleren, maken sommige organisaties 'signaleren' zelfs tot een prestatie-indicator; een professional of afdeling die weinig signaleert, wordt op het matje geroepen.

De auteurs constateren een juridische en bestuurlijke druk om pseudo-risicodiagnostiek te bedrijven, en hebben nog meer onderbouwde bezwaren.
\end{abstract}

In het WRR-rapport De Staat van informatie (2011) betogen Keymolen en Prins dat "het debat over de digitalisering van de jeugdzorg, met de introductie van de Verwijsindex Risicojongeren als sprekend voorbeeld, armoedig is. De discussie beperkt zich tot de tekentafelontwerpen op rijksniveau, terwijl de echt prangende vragen en dilemma's eigenlijk op lokaal niveau verscholen gaan' (p. 339). Voor de wet Verwijsindex Risico jongeren (VIR) die in 2010 is aangenomen geldt dat zeker. Die wet verplicht gemeenten om afspraken te maken met organisaties die met kinderen werken om zich, meestal via aan lokale index, aan te sluiten op de landelijke Verwijsindex, zodat er een landelijk dekkend signalerend netwerk ontstaat. Nu is de Verwijsindex opgenomen in de nieuwe Jeugdwet, maar in de discussie over die wet kwam het onderwerp wederom amper aan bod. Dat is onterecht.

* Prof. dr. Klasien Horstman is hoogleraar Filosofie van de Publieke Gezondheidszorg. Inge Lecluijze MSc doet promotieonderzoek naar de Verwijsindex. Dr. Bart Penders is universitair docent en prof. dr. Frans Feron is hoogleraar Sociale Geneeskunde, in het bijzonder Jeugdgezondheidszorg. Ze zijn allen werkzaam aan de Universiteit Maastricht. Reactie? E-mail naar k.horstman@maastrichtuniversity.nl. 
De VIR is een risicoregelreflex
Vanaf het begin van de 21ste eeuw is veel geïnvesteerd in de ontwikkeling van lokale ICT-systemen en een nationale variant, de VIR. Zowel in de memorie van toelichting bij de VIR als in de vele convenanten, nota's en nieuwsbrieven over de Verwijsindex is sprake van twee doelen: vroegopsporing van alle risicokinderen en samenwerking tussen professionals. De Verwijsindex kan gezien worden als een typisch voorbeeld van risicoregelreflex: wetgeving die dwingt tot invoering van ICT creëert de verwachting dat ICT geweldsincidenten en andere calamiteiten met kinderen kan voorkomen. Hoewel grote ICT-operaties nooit 'simpel' zijn, wordt de Verwijsindex gepresenteerd als een 'simpel instrument' dat ervoor zal zorgen dat er 'geen kinderen tussen wal en schip vallen'. De onbedoelde gevolgen van de sturingsfilosofie achter de Verwijsvraag wijzen echter in een andere richting.

\section{Een pragmatisch perspectief}

Met de ontwikkeling van de Verwijsindex is veel geld, tijd en energie besteed aan 'implementatie' ervan in de praktijk. Wij hebben het implementatieproces van een specifieke lokale ICT-variant in een provincie gedurende vier jaar intensief gevolgd. Daarbij hebben we theoretisch geput uit wetenschaps- en techniekstudies: deze discipline analyseert hoe technieken genetische testen, gasboring-

installaties, mobiele telefoons enzovoort - zich ontwikkelen in interactieprocessen tussen tekentafel en praktijk (Jasanoff et al., 1995). Vanuit dit gedachtegoed kun je eigenlijk niet spreken van 'implementatie' van een techniek: dat veronderstelt immers dat de techniek 'af' is en alleen maar in de praktijk 'uitgerold' hoeft te wor- den, en als dit eenrichtingverkeer stokt, krijgt de praktijk doorgaans de zwarte piet. Vanuit wetenschaps- en techniekstudies moeten zaken die zich in een laboratoriumsetting hebben bewezen de real life-test nog ondergaan, en als die niet slaagt, dan is reflectie op het design geboden. Vanuit dit perspectief zijn geslaagde technologische projecten geen geslaagde implementaties, maar geslaagde interacties.

Daarnaast zijn we geïnspireerd door noties uit de rechtsfilosofie en de beleidssociologie. In het werk van bijvoorbeeld Schuyt (1983), Glastra van Loon (1980) en Van Gunsteren (1994) wordt een pragmatisch filosofische opvatting van regels uitgewerkt, die inhoudt dat regels niet hun eigen uitvoering dicteren maar worden waargemaakt in het handelen. Er zijn dus per definitie geen een-op-een-relaties tussen wet en praktijk. Deze pragmatische filosofie van regels impliceert een sterke relativering van het idee dat een maatschappij kan worden gestuurd en gecontroleerd door wetgeving. In het verlengde hiervan hebben beleidssociologen zoals Van der Veen (1990) in onderzoek naar de wetten van de verzorgingsstaat het uitgangspunt van Lipsky ter harte genomen: '... public policy is actually made in the crowded offices and daily encounters of street-level workers'. Zij hebben laten zien dat sociaal beleid in de praktijk wordt geconstrueerd: de betekenis van beleid wordt niet bepaald door de tekst of de macht van de wet, maar door sociale processen in praktijken. Dat impliceert dat beleidsmakers beperkt kunnen sturen. Ze kunnen echter wel publieke leerprocessen organiseren over de (on)bedoelde gevolgen van beleid. Om die publieke leerprocessen mogelijk te maken, moet de praktijk echter 
'gekend' worden, en dat is met de praktijk van het jeugdbeleid niet het geval. De praktijk van het jeugdbeleid is voor veel beleidmakers een black box, gerepresenteerd in schema's en modellen, en daardoor kan de mythe van sturing in tact blijven. Natuurlijk zijn moderne bestuursfilosofieën over interactie, dialoog, vertrouwen niet aan het jeugdbeleid voorbij gegaan, maar zolang er weinig inzicht is in de dynamiek van praktijken, wordt er over en van die praktijken weinig geleerd. Om inzicht te verwerven in de praktijk van de implementatie van de Verwijsindex Risicojongeren hebben wij door middel van een etnografische methodologie het implementatieproces gedurende vier jaar in een provincie van dichtbij gevolgd (Lecluijze et al., 2013; 2014). We hebben een spoor van landelijke en lokale documenten gevolgd (beleidsrapporten, convenanten, implementatieplannen, draagvlakanalyses, evaluaties, et cetera.). We zijn drie jaar lang aangeschoven bij vergaderingen van beleidsmakers en uitvoerders en hebben trainingen ketencoördinatie, gebruikersmiddagen, een casusoverleg en overleg tussen ketencoördinatoren geobserveerd. Daarnaast hebben we 70 interviews gedaan met professionals en beleidsmakers, en een focusgroep met trainers en ouders en vijf met jongeren. Om zicht te krijgen op lokale contexten hebben we bij vier verschillende gemeentes gekeken, en hebben we ook een kijkje genomen in andere regio's in Nederland en in Engeland. In dit artikel gaan we in op een element van de analyse, namelijk het wegregelen van leerprocessen over de doelen van de Verwijsindex.

\section{Een bestuurlijk gedrocht}

In het bestuurlijke discours over de Verwijsindex is deze gepresenteerd als een 'simpel' instrument dat alleen maar 'dat-informatie' en geen 'watinformatie' bevat. Maar vroegsignalering vraagt de facto wel om een inhoudelijk professional oordeel over de vraag of er sprake is van een risicokind: de Verwijsindex gaat dus wel om wat-informatie. Professionals hebben dat van meet af aan problematisch gevonden, want wanneer is een kind een risicokind? Er zijn diverse pogingen gedaan om het begrip risicokind te definiëren. In 2009 werden bijvoorbeeld landelijk 'meldcriteria' opgesteld. Los van de problematische associatie van 'signaleren' met melding van kindermishandeling, bieden de meldcriteria niet veel aanknopingspunten: ze noemen bijvoorbeeld 'de jeugdige is van school of kinderopvang gestuurd', 'de jeugdige woont in een krappe woning' en 'er is onenigheid in het gezin of tussen de ouders'. Deze alledaagse situaties zijn een reden voor 'melding' als er sprake is van 'een ongunstig effect op de ontwikkeling van een jeugdige', maar het is aan de betreffende professional om dat zelf in te schatten. Wat geldt als onenigheid tussen ouders? Wat als leerprestaties van een kind verminderen? Een onderwijzer ziet dat anders dan een jeugdarts, en hebben niet alle kinderen 'een kans op ontwikkelingsproblemen'?

'We hebben ook steeds het dilemma van welke kinderen komen er nou in. [...] Een moeder met een vraag over een kind dat nog in zijn bed plast, waar je misschien een extra gesprekje aan waagt, moet die in de Verwijsindex?', zo vraagt een jeugdarts zich af. Een jongerenwerker stelt: 'Wij zitten wel mooi in die positie dat wij
De praktijk is voor veel beleidmakers een black box 
De VIR geeft een ongefundeerd professioneel oordeel heel veel zien [...]. Waar wij echt zorg hebben? Het is voor ons heel lastig om dat constant in die weegschaal te leggen.'

\section{Pseudo-diagnostiek}

Door deze verschillen is de betekenis van een signaal onvoorspelbaar. Veel gemeentes en organisaties hebben geprobeerd zelf helderheid te verschaffen en er is inmiddels een woud ontstaan van operationaliseringen: 'gebruikersprotocol', 'definities', 'handleiding', 'reglement', 'procedure', 'werkinstructie', of van 'regels', 'richtlijnen' en 'digitale routekaarten', 'spoorboekjes', 'handreikingen', 'stroomschema's', 'determinantenbladen' en 'trainingen vroegsignalering' enzovoort. Deze pogingen om problemen rond het concept 'risicokind' te temmen, slagen niet, wat alleen maar leidt tot meer schema's en richtlijnen en niet tot reflectie. Vroegsignalering van risicokinderen in de Verwijsindex komt namelijk neer op het geven van een ongefundeerd professioneel oordeel. Het ongefundeerde karakter van een signaal schuilt niet in de deskundigheid van de professional, maar in de dwang voor de crèchemedewerker, onderwijzer en jeugdarts om contextuele observaties te de-contextualiseren in een systeem met een onduidelijke doelstelling. Is de Verwijsindex een databank van vermoedens over mogelijke problemen voor een kind in-de-toekomst of een systeem voor hulpverleners voor coördinatie van concrete zorg in het hier-en-nu? Is het een databank van pseudo-diagnoses of een telefoonboek voor professionals? Doordat de Verwijsindex dwingt tot digitale pseudo-diagnostiek creëert ze professionele weerstand tegen dit instrument. Reguliere beleidsevaluaties merken dat echter niet op omdat deze in dienst staan van sturing en niet van leren.

\section{Prestatie-indicator}

Het wettelijk kader van de Verwijsindex betekent juridisering van het signaleren van risicokinderen: in geval van calamiteiten kijkt de inspectie of een kind is gesignaleerd. Gemeenten en organisaties investeren dus veel in 'implementatie' en in dat proces wordt 'geslaagde implementatie' geïdentificeerd met 'veel signaleren'. Nationale, lokale en regionale beleidsevaluaties, die de wet als gegeven aannemen en geen oog hebben voor de onbedoelde gevolgen van de Verwijsindex, concluderen echter vrijwel allemaal 'er wordt niet genoeg gesignaleerd' en roepen professionals op om meer te signaleren: 'bevorderen gebruik', 'vergroot meldingsbereidheid', 'werken aan een verbeterplan', 'deskundigheidsbevordering', 'meer gebruik', 'meer aandacht voor implementatie', 'signaleringssysteem uitbreiden', 'professionalisering signaalgevers', 'beter gaan signaleren'. Sommige organisaties maken 'signaleren' zelfs tot een prestatie-indicator.

'Iedereen heeft natuurlijk zoiets, ik word straks afgerekend op mijn quota meldingen, dus dan zal ik dat maar doen, of het nou wel of niet zinvol is', zo zegt een jeugdarts. Een professional of afdeling die weinig signaleert, wordt op het matje geroepen. Om de wet toch succesvol te implementeren, worden ten behoeve van lokale en nationale bestuurders managementrapportages gemaakt met fraaie staafdiagrammen en tabellen van aantallen signalen - per regio, gemeente, organisatie of professional, maar niemand weet wat de absolu- 
te cijfers of groei en afname van aantallen signalen betekenen, omdat niemand weet wat een signaal betekent. Deze kwantitatieve rapportages suggereren sturing en controle, maar verhullen dat niemand weet wat een signaal en de oproep om meer te signaleren betekent.

Juridisering van de Verwijsindex bewerkstelligt een perverse managerial push tot signaleren: hoe meer signalen des te beter. De ruimte om te leren over basale weeffouten in de Verwijsindex, zoals het naïeve gebruik van de noties ‘vroegsignaleren' en 'risicokind', wordt in dit top-down georganiseerde implementatieproces weggeregeld.

\section{Ouders niet gehoord}

De vraag waarom professionals huiver hebben voor een signaal wordt vaak beantwoord met verwijzing naar de handelingsverlegenheid van professionals in het jeugdveld. Door specifieke historische ontwikkelingen rond publieke verantwoordingstechnieken voor professioneel werk in het sociale en sociaal-medische domein zitten professionals in een spagaat tussen politiek en burgers (Horstman, 2004). Veel professionals vinden het inderdaad moeilijk om ouders te moeten informeren over een signaal. Ze twijfelen erg over de betekenis van een signaal en ervaren ook dat de consequenties ervan redelijk onvoorspelbaar zijn. Ze zien risicosignalering als een schending van de privacy van het kind, omdat een signaal kinderen 'besmet', 'stigmatiseert' of een 'stempeltje geeft'. Of ze zijn bang dat de relatie met ouders wordt beschadigd. Zo vertelt een stafverpleegkundige: 'Als ouders dan de deur dicht gooien als reactie - als jij gaat melden in dat sys- teem dan kom je er niet meer in - dan ben je ze kwijt. En dat willen wij niet.'

Wanneer een professioneel beroep op 'het belang van de relatie met ouders' door beleidsmakers wordt afgedaan als uitingen van zwakte van de beroepsgroep, wat op zich zelf niet onjuist is, wordt miskend dat deze uitlatingen ook de verwarring over de ambities van de Verwijsindex reflecteren. Als er sprake is van handelingsverlegenheid onder professionals, zal juridische en bestuurlijke druk om pseudo-risicodiagnostiek te bedrijven die verlegenheid niet verkleinen. In die zin is de Verwijsindex een slecht professioneel instrument: betekenisloze staafdiagrammen maken een professionele groep zwakker in plaats van sterker.

De huiver van professionals om te signaleren, reflecteert ook de afwezigheid van de stem van ouders in het jeugdbeleid in het algemeen en in de ontwikkeling van de Verwijsindex in het bijzonder. Ouders zijn in dit proces van meet af aan als 'object' en 'vijand' geconstrueerd, en ze hebben weinig verweer tegen signalering. 'Waarom kunnen wij eigenlijk niet signaleren?', vroegen ouders. Een jongere zei: 'Ik vind het eigenlijk wel heel apart dat iemand als een leraar en iemand als een huisarts [...] dat die zo'n kruisje kunnen zetten en ouders, die het kind natuurlijk door en door kennen, dat dan niet kunnen.'

De Verwijsindex belichaamt het idee dat professionals het beter met kinderen voor hebben dan ouders. De beleidsmatige misser om ouders niet serieus te nemen in het jeugdbeleid ligt nu op het bord van professionals die ouders moeten informeren over pseudo-diagnostiek, en dat lastig vinden.
De VIR bewerkstelligt een perverse managerial push tot signale- 
Ouders hebben weinig verweer tegen signalering

\section{Leren over ICT}

Uit ons onderzoek naar de praktijk van de implementatie van de Verwijsindex is duidelijk geworden, net zoals in vrijwel alle andere evaluaties, dat de Verwijsindex geen succes is. Terwijl de meeste evaluaties van de Verwijsindex het beleid als gegeven zien en concluderen dat er meer gesignaleerd moet worden, is onze conclusie dat te sterke sturing op implementatie van de Verwijsindex reflectie op, en discussie over, basale weeffouten en perversiteiten in de Verwijsindex onmogelijk heeft gemaakt. Er was en is geen ruimte om publiek en professioneel te leren, terwijl die ruimte in de transitie dringend noodzakelijk is. Het is belangrijk voor de kwaliteit van professioneel werk dat scherp onderscheid wordt gemaakt tussen een samenwerkingsinstrument voor professionals en professionele risico-oordelen over kinderen, gezinnen of ouderen. Deze doelen moeten niet zoals in de Verwijsindex - op een hoop worden gegooid.

Daarnaast is het van belang dat analoog en contextueel professioneel werk niet gejuridiseerd wordt: een Verwijsindex moet niet bij wet geregeld worden. De ruimte die dan ontstaat, kan gebruikt worden voor publieke en professionele discussie over de vraag wat voor soort informatie waar eigenlijk nodig is, voor wie, om adequate zorg mogelijk te maken. In plaats van de ontwikkeling van informatiesystemen met megalomane ambities van vroegsignalering die leiden tot het domweg verzamelen van zoveel mogelijk 'risicosignalen', kan dan gewerkt worden over informatiesystemen die praktische doelen van professionals en burgers dienen. Dat burgers - ouders en jongeren - daar bij betrokken worden, moet vanzelfspre- kend zijn. Dat privacy in de context van experimenten met sociale wijkteams en andere vormen van zorg opnieuw onderwerp is van discussie, is van groot belang voor het publieke vertrouwen in professionals. Ten slotte, uit een simpel voorbeeld als de Verwijsindex blijkt hoezeer professionals die werken met kinderen en jeugd klem zitten tussen politiek en burgers, en hoe verlammend dit werkt. Het weerwerk dat ze leveren is echter minimaal. Dat roept de vraag op of de opleidingen wel adequaat zijn. De veranderingen in het jeugddomein vragen meer dan ooit dat professionals opgeleid worden tot reflexieve en kritische professionals en niet alleen als uitvoerders van beleid.

\section{Literatuur}

E. Keymolen, J.E.J. Prins, Jeugdzorg via systemen. De Verwijsindex Risicojongeren als spin in een digitaal vangnet, in: D. Broeders, M.K.C. Cuijpers, J.E.J. Prins (red.) De staat van informatie. WRR. Amsterdam, Amsterdam University Press, 2011, 293-348.

S. Jasanoff, G.E. Markle, J.C. Petersen, $T$. Pinch (eds.) The handbook of science and technology studies. London, Sage, 1995.

C.J.M. Schuyt, Tussen macht en moraal. De plaats van het recht in verzorgingsstaat en democratie. Alphen aan de Rijn, Samsom, 1983.

J.F. Glastra van Loon, De eenheid van het handelen, Opstellen over recht en filosofie. Amsterdam/Meppel, Boom, 1980.

R. van der Veen, De sociale grenzen van beleid. Leiden, Stenfert Kroese, 1990.

K. Horstman, Managers en uitvoerende mogen geen neutrale vehikels zijn van overheidsbeleid. 
In: Nederlands tijdschrift voor Jeugdzorg, 2004, 8(3), 142-149.

I. Lecluijze, B. Penders, F. Feron, K. Horstman, Innovation and Justification in Public Health: The Introduction of the Child Index in the Netherlands, in: D. Strech, I. Hirschberg, G. Marckmann (Eds.), Ethics in Public Health and Health Policy. Concepts, methods, case Studies. Springer International, 2013, 153-173.
I. Lecluijze, B. Penders, F. Feron, K. Horstman, Scripted collaboration: digitalisation of care for children, in: Penders B, Vermeulen N, G Parker J N. (eds). Collaboration across Health Research and Medical Care: Healthy Collaboration. Farnham: Ashgate, 2014. 


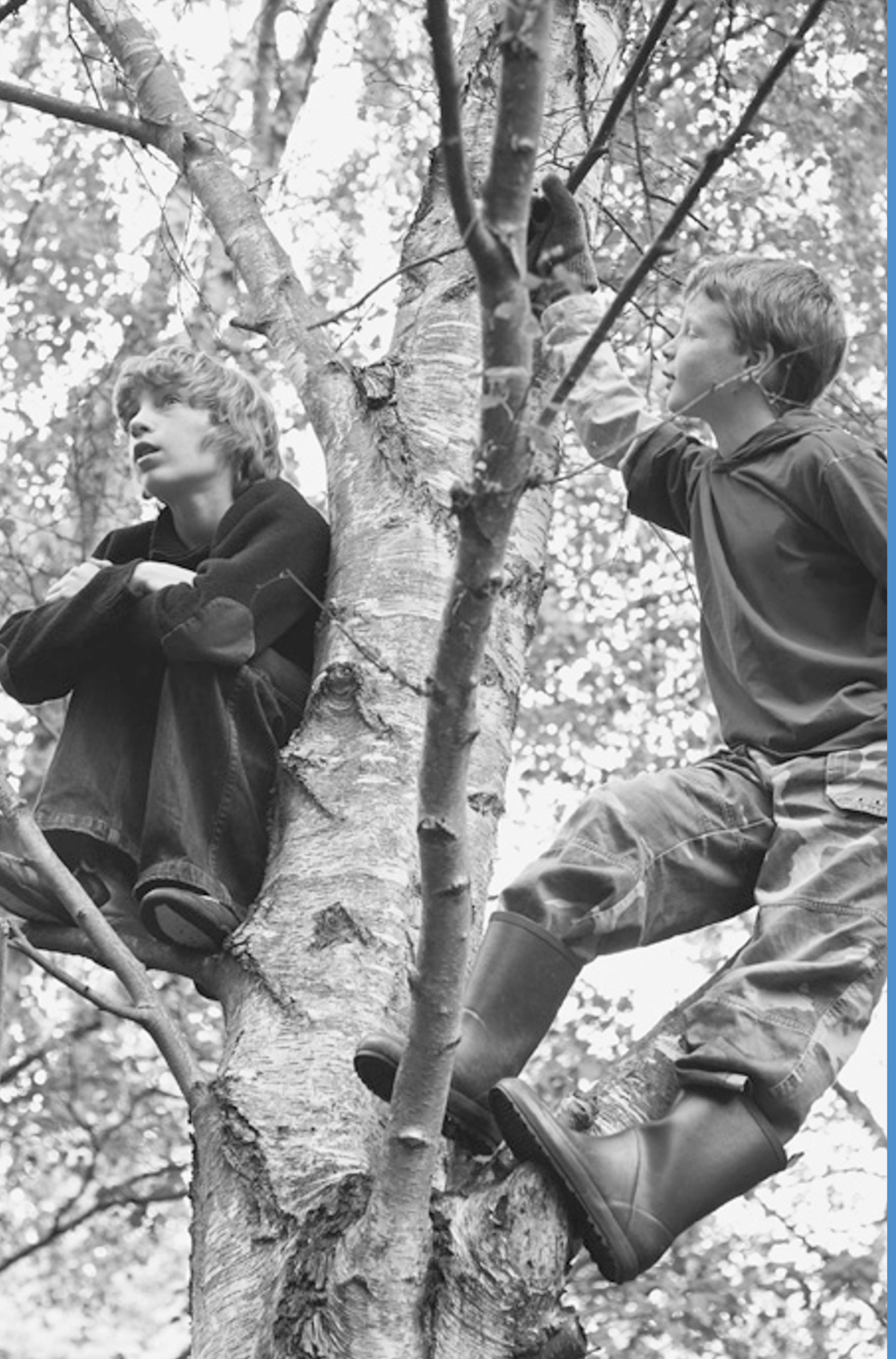

